\title{
Study of the Desulfurization Process and Gas-Solid-Liquid Phase Distribution under the Complex Humidification Conditions in Dense Tower
}

\author{
Baorui Liang', Cunyi Song ${ }^{1}$, Qian Jia ${ }^{1}$, Donghui Zhang', Xiaoyue Sun ${ }^{2}$, Fan Pan $^{3}$ \\ ${ }^{1}$ School of Civil \& Environment Engineering, School of Civil \& Environment Engineering, Beijing, China; ${ }^{2}$ Kunming Iron \& Steel \\ Group Co. Ltd., Kunming, China; ${ }^{3}$ Huayun Tianlang Environmental Protection Co. Ltd., Kunming, China. \\ Email: yhhy86@126.com
}

Received January $5^{\text {th }}, 2012$; revised February $7^{\text {th }}, 2012$; accepted March $8^{\text {th }}, 2012$

\begin{abstract}
In making the gas-solid-liquid phase analysis, based on the collaborative study of the internal and external humidification ratio of desulfurization efficiency, determine the humidifier ratio within $60 \%$ to $75 \%$, that can make the best balance between the respective merits of a simple tower humidifiers tower humidifier way, optimizing the overall desulfurization reaction, effectively reducing the sticky wall, stick in the desulfurization efficiency and reduce the wall to achieve a balance between the balance, without increasing the sorbent and process water, under the premise can promote the desulfurization reaction, improve the desulfurization sorbent utilization and efficiency, help desulfurization reaction system is stable, efficient and economic operation, the gas-liquid-solid three-phase to achieve better synergy.
\end{abstract}

Keywords: Composite Humidification; Dense-Phase FGD; Turbulence Intensity

\section{Introduction}

Currently, 200 kinds of domestic and total sulfur dioxide emissions developed technology, which is a common means of flue gas desulfurization by reaction products of the form and conditions can be divided into the wet desulfurization end, semi-dry, dry in three ways [1]. One semi-dry with a small footprint, the system is simple, low cost investment operation, no wastewater, etc., in the domestic market has a wide range of flue gas desulfurization prospects [2]. However, compared with the wet, the efficiency and sorbent of semi-dry desulfurization still have low utilization problems, with the introduction of new environmental standards, making the semi-dry technology in industrial applications by certain constraints [3]. For semi-dry question, researchers take the gas-solid phase as the starting point, optimizing the inlet flow of flue gas desulfurization tower, improve air-solid two-phase uniformity to improve the efficiency of flue gas desulfurization $[4,5]$, or a different device to suppress the flow of sticky wall phenomenon [6], or by optimizing the spray nozzle itself features to improve the desulfurization efficiency [7], but these studies only examined a single tower humidifier way, the lack of solid-liquid twophase concentration distribution and influencing factors, and this is the solution sticky wall and improve the desulfurization efficiency of the key issues.
This paper describes a new type of dense semi-dry flue gas desulfurization process [8], the process uses a unique complex humidification and sorbent cycle way in improving the desulfurization efficiency and sorbent utilization at the same time, avoiding the sticky wall desulfurization agent, compaction and other issues, will help the system safe and stable operation, without increasing the amount of sorbent and process water conditions, by way of complex humidification, the desulfurization efficiency must be improved.

\section{Experimental Principle}

Desulfurization reaction, including two different physical and chemical processes: one is the desulfurizer and desulfurization liquid droplet collision ion reactions; one is in the flue gas desulfurization agent adsorption of water vapor to improve their surface layers of water molecules in gas-solid reaction. Synergies between these two processes to complete desulfurization process, the controlling factors of $\mathrm{SO}_{2}$ in the gas phase to the slurry droplet surface diffusion rate, slurry drops in $\mathrm{Ca}(\mathrm{OH})_{2}$ dissolution rate of ionization and diffusion, product layer diffusion, etc. $[9,10]$. Desulfurization reaction of ionic liquid which is considered the most effective in improving efficiency.

Ensure that the total amount of water in the same ex- 
periment under the premise, Using a humidifier inside and outside the complex way of humidification. Inside and outside the humidifier water through a reasonable ratio to optimize the process of desulfurization tower, the main reaction zone as far as possible ionic liquid and efficient desulfurization reactions. Water tower humidifier is directly injected into the reaction to the desulfurization tower, the drop in the tower by the wet into the dry state of the drying process while the process for the desulfurization reaction; tower humidifier is the reaction of water with the sorbent in the tower independent external humidification mixer complete the digestive process, and then put the mixed material into the desulfurization tower for the desulfurization reaction. (According to temperature changes, by adjusting the ratio of internal and external humidifier, change the desulfurization tower water in a form and distribution of the main reaction zone to ensure the effective number of droplets while increasing the droplet, desulfurizer, sulfur dioxide and other gas-liquid solid three-phase collision frequency, to ensure fast and efficient completion of reaction). Composite humidifier water use is mainly to change the way gas-solid little effect on the tower, in the study of gassolid-liquid phase synergies, the main parameters in liquid-based.

In order to study dense reasonable desulfurization tower in a closed environment to complete the desulfurization reaction, made a gas-solid-liquid phase co-analysis: gassolid-liquid phase of the distribution of the droplets and direct impact on the fresh sorbent collision activation, circulating ash in wet droplets and particles reunion, efficient use of water, desulfurization reaction and reaction rate, and many other processes, the complexity of threephase distribution, it is difficult to achieve uniform distribution of the absolute sense. Gas $\left(\mathrm{SO}_{2}\right)$ has a good diffusion can be evenly distributed in the reactor, assuming that gas and liquid phase, solid phase there is a synergistic unity; focus on analysis of liquid-solid two-phase tower in the dense phase concentration, droplet-containing agglomeration of wet particles collide, stick the tower wall and other issues; by gas desulphurization efficiency characterization of solid-liquid phase is assumed to achieve better synergy effects.

Dense-phase desulfurization tower in the device during operation, is the fresh sorbent into the tower, humidifier and recycling gray water tower in the dense phase was mixed sorbent moisture content at $3 \%$ to $5 \%$ in hightemperature smoke gas was quickly turned into steam, part of the water as cooling water, reducing the response to water ratio. Thus, by a certain quality of steam injected into the flue gas temperature to reduce the way as the analog tower humidifier. Amount of steam injected into the flue gas temperature drop with the relationship through the heat balance calculation to determine, is calculated as follows:

$$
\begin{aligned}
& \mathrm{C}_{\mathrm{g}} \times \mathrm{T}_{\mathrm{gi}} \times \mathrm{Q}_{\mathrm{Vg}}+\mathrm{C}_{\mathrm{w}} \times \mathrm{T}_{\mathrm{w}} \times \mathrm{M}_{\mathrm{w}} \\
& =\left(\mathrm{C}_{\mathrm{g}} \times \mathrm{V}_{\mathrm{g}}+\mathrm{C}_{\mathrm{vp}} \times \mathrm{Q}_{\mathrm{Wg}}\right) \times \mathrm{T}_{\mathrm{ge}}
\end{aligned}
$$

Where $C_{g}, C_{w}, C_{v p}$ refers to gas, water, water vapor at specific heat, $T_{w}, T_{g i}, T_{g e}$ means water temperature, the temperature before humidification, the temperature after humidification, humidification temperature before, after humidification temperature, $\mathrm{Q}_{\mathrm{Vg}}, \mathrm{Q}_{\mathrm{Wg}}$ refers to the amount of smoke and water spray.

\section{Course of the Experiment}

The experimental flow chart shown in Figure 1.

Test system consists of dense tower flue gas desulfurization equipment, bag filter unit, feeding equipment, ash recycling plant, tower humidifier device, humidifying tower unit, composed of fan support. DC tower entrance way flow, with insulation tower, tower wall with a number of flange interfaces for PDA measurement. Humidification system is divided into three parts, one for cooling the flue gas humidification (American Spray's JAC-SU22B dual-fluid spray nozzle), part of the coarse particles for the humidification system (coarse sorbent) (Southern Pumps QDL4-140 light vertical multistage centrifugal pump) and one for fine particles of humidification (Wuxi Wang Jie humidification horizontal axis mixer), particles collected from the tail of the bag filter. To ensure the consistency of experimental conditions, the entrance point of the flue at a wetting front, dense tower entrance with K-type thermocouple and digital display, export with testo 635 temperature and humidity tester (temperature measuring range: $0 \%-100 \% \mathrm{RH}$, accuracy: $\pm 2 \% \mathrm{RH}$; temperature measuring range: $0^{\circ} \mathrm{C}-200^{\circ} \mathrm{C}$, accuracy: $\pm 0.1^{\circ} \mathrm{C}$ ). Measurement parameters include:

1) dynamic pressure measurement flow (flow rate) and system resistance.

2) screw conveyor and belt scale for measuring the fresh sorbent added measure.

3) two-fluid nozzle cooling humidifier done by the Italian ITAP-361-type water pressure reducing valve and the U.S. MB-T70-type air valve controlling water and air, respectively, the pressure regulating water flow path, atomizing air through the compressor provided by highpressure water pumps provide high pressure micro HSP11050 type.

4) Denmark Dantec company developed laser particle dynamic analyzer (Particle Dynamic Analyzer, referred to as PDA).

Entrance test parameters, measuring points as shown in Table 1, the table relative height (H/D) to partition the low-end basis, the relative radius $(\mathrm{r} / \mathrm{R})$ is a unilateral basis tower centerline. Data processing, the parameters of 


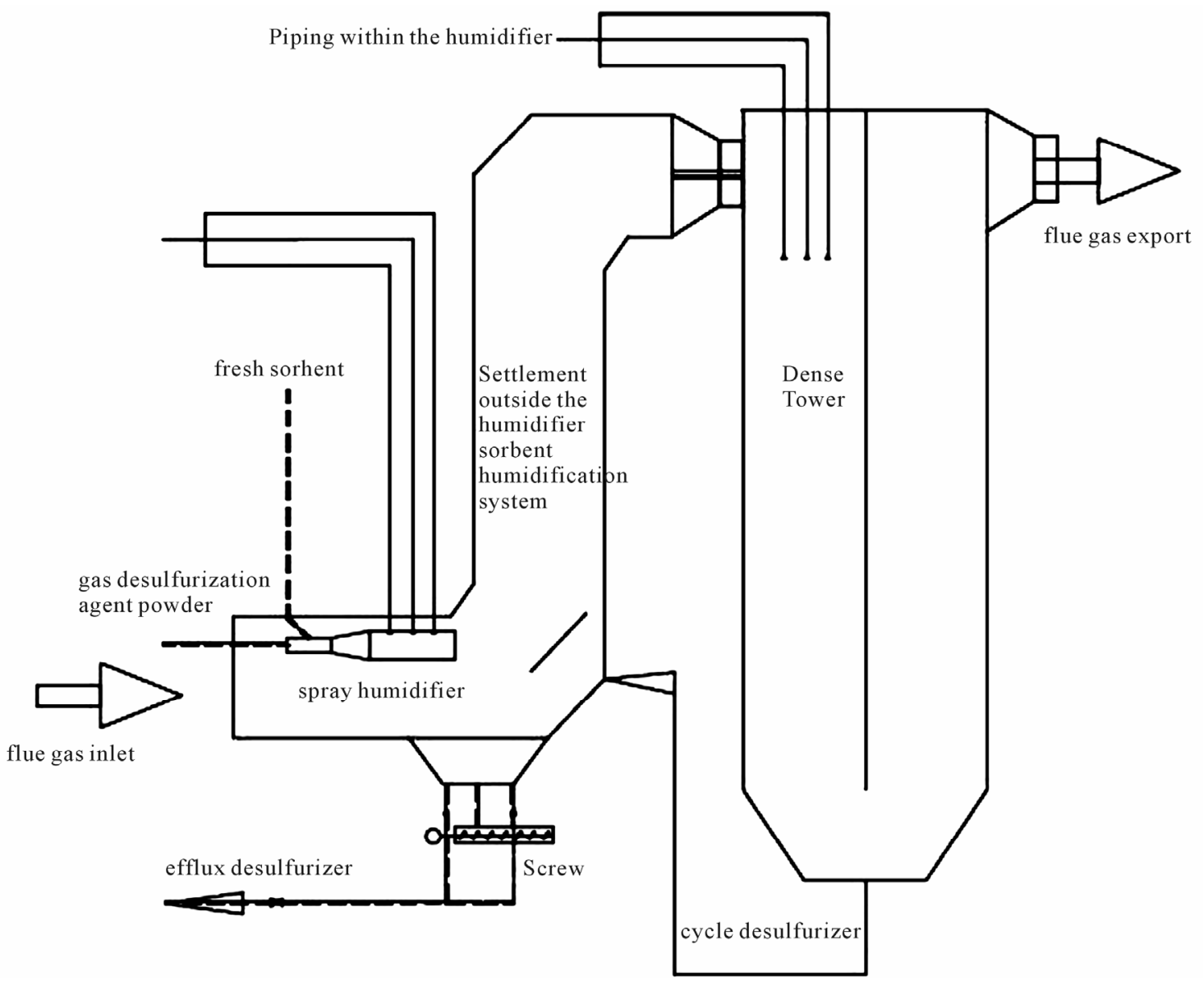

Figure 1. The test flow chart.

Table 1. The arrangement of test measuring points.

\begin{tabular}{lcccc}
\hline conditions & $\begin{array}{c}\text { inlet particle } \\
\text { concentration }\left(\mathrm{g} / \mathrm{m}^{3}\right)\end{array}$ & $\begin{array}{c}\text { humidifier } \\
\text { water }(\mathrm{t} / \mathrm{h})\end{array}$ & $\mathrm{r} / \mathrm{R}$ & $\mathrm{H} / \mathrm{D}$ \\
\hline & & 0.1 & 0.5 \\
& & 0.2 & 1 \\
$\begin{array}{c}\text { gas-solid phase } \\
\text { measurement }\end{array}$ & 60 & $/$ & 0.3 & 1.5 \\
& & 0.4 & 2 \\
& & 0.5 & 2.5 \\
\hline $\begin{array}{l}\text { liquid meas- } \\
\text { urement }\end{array}$ & & 0.6 & 3 \\
& 9 & 0.7 & 3.5 \\
& & 0.8 & 4 \\
& & 0.95 & 5 \\
\hline
\end{tabular}

the radial axis-symmetric manner, in order to simplify the diagram, depicting in graphic representation only when the one-way axis. To facilitate measurement, the testing process points to hot and cold state, under testing in cold air-solid two-phase field and concentration of solid particles; in the hot state test parameters such as droplet velocity and concentration, and thus of the liquid droplet evaporation, gas and solid-liquid mass transfer phase of the collision, moisture particles reunion, and the sticky wall and other issues.

\subsection{The Gas-Solid Phase Velocity Distribution}

Average velocity in the test is $5.3 \mathrm{~m} / \mathrm{s}$, inlet particle concentration is $60 \mathrm{~g} / \mathrm{m}^{3}$, the gas-solid two phase relative to the axial velocity distribution (relative to the axial velocity is defined as the axial velocity and mean velocity ratio), shown in Figure 2.

In Figure 2, the gas-solid two-phase axial center of the high speed shows the trend of low wall, which is consistent with previous studies. In the dense top of the tower, by gradually expanding section of the impact speed of this trend is most evident; the lower of the dense smoke along the tower, the flatter of the radial distribution of axial velocity, when the $\mathrm{H} / \mathrm{D}>3$ after, near the wall at the gas-solid flow rate is relatively low, analysis of the reasons may be stranded by the wall effects; tower uses a 


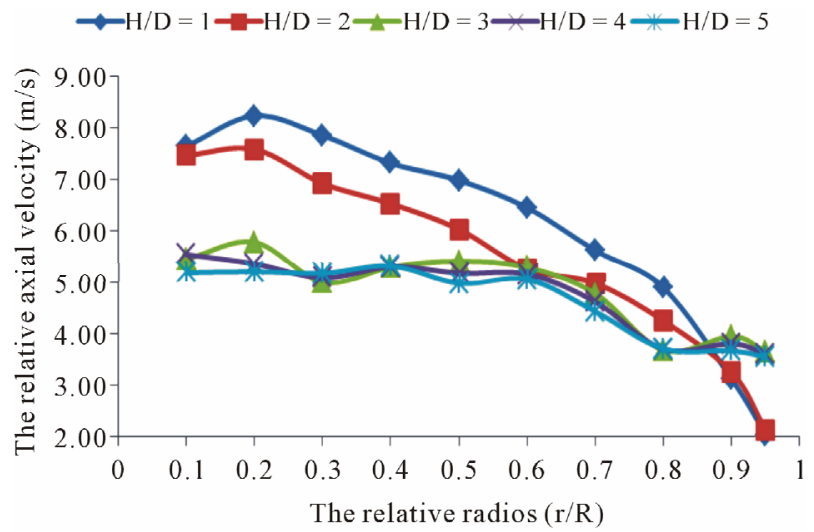

Figure 2. The relative of axial velocity for gas-solid phase.

gravity flow along sport, and little change in tangential velocity, the relative slip velocity between gas-solid will small, is not conducive to the conduct of heat and mass transfer in practical engineering applications are the wind plant is located, to increase the gas flow near the wall turbulence intensity, enhance the flow turbulence intensity, the reunion of dispersed particles as soon as possible by air turbulence, the formation of a strong back-mixing phenomena and turbulence intensity, enhanced mass transfer.

\subsection{The Concentration Distribution of Solid Particles}

As the particle size distribution is difficult to get the tower are of the true concentration, the relative particle concentration in dense phase characterization of the tower desulfurization agent particle concentration (measured points sorbent particle concentration and particle concentration ratio of the average conditions), Figure 3 into several sections, the average particle concentration.

Figure 3 shows the different sections, the dense-phase particle distribution along the centerline of the tower gradually decreased, increased concentrations occur in the near-wall phenomenon, with the flue gas flow in the tower, reducing the high concentration range, the overall concentration of stabilized the state. When $\mathrm{H} / \mathrm{D}>3$, each cross-section of average relative particle concentration fluctuations around 1, close to conditions calculated to illustrate the gravity along the dense-phase flow of particles along the tower to achieve better homogenization effects; when $\mathrm{r} / \mathrm{R}>0.8$ after each section of the relative particle concentration on the emergence of a uplift trend in Figure 3 shows the tower in the dense phase gas flow under gravity along the movements in the process, the near-wall velocity is lower than the center, sports close to the laminar flow state, the $\mathrm{r} / \mathrm{R}$ in the range of 0.8 to 1.0 , the solid particles appeared reunion and stick wall phenomenon, which would limit the mass transfer process is

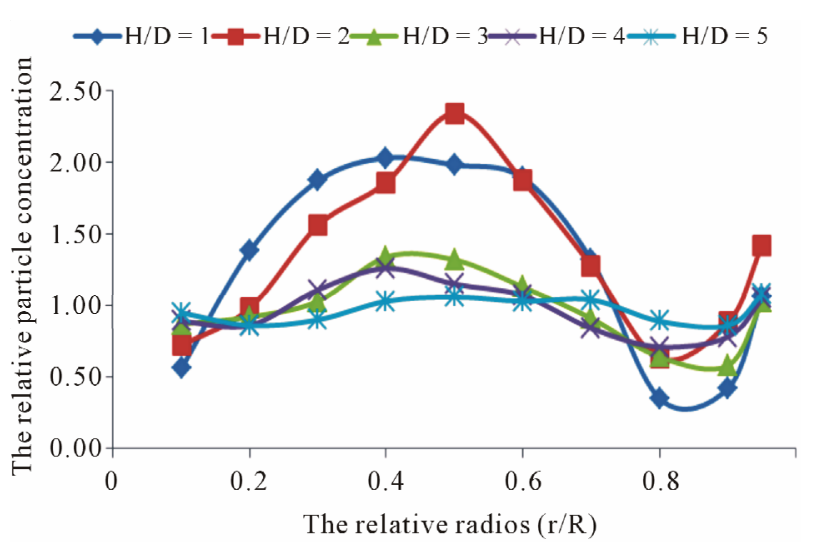

Figure 3. The particle size distribution under different sections.

not conducive to desulfurization process, in mixing engineering applications based chain device, the device in the dual role of both the wind under the accelerated particles spread evenly in each section, making the particles near the wall in the speed of decay, the axial velocity is still there, along the dense-phase particles in the downward movement of the tower to the process continue into the center of the mainstream area, the formation of turbulence within the circulation area, the uniformity of the particles as the tower is full of the dense phase, dense phase desulfurization create the best atmosphere.

\subsection{The Concentration Distribution of Droplet}

The PDA can not directly detect the particles dense droplets tower, so the figure is mainly characterized by different compound humidifier working conditions, through the nozzle atomized water droplets in the dense phase spread of the evaporation tower. Under different conditions of different humidification $\mathrm{r} / \mathrm{R}$ under the droplet concentration was analyzed, obtained as shown in Figure 4.

See from Figure 4, in the composite humidification conditions, the droplet concentration near the wall was significantly lower than the desulfurization tower on the other radial droplet concentration, indicating the way composite humidifier can effectively reduce the desulfurization tower sticky wall problem. When $0.4<\mathrm{r} / \mathrm{R} \leq 0.6$, the unit effective volume of the droplet concentration maximum, indicating that in this context is the best spray nozzle radius; this time, the proportion of water within the humidifier increases the total amount of water $67 \%$ to $73 \%$ range, the maximum droplet concentration. The figure shows that with increasing water tower humidifier, different $r / R$ conditions, the maximum droplet concentration appeared different, probably due to the humidifier water pump and spray nozzle has been identified under the premise, because humidifiers within changes in the 


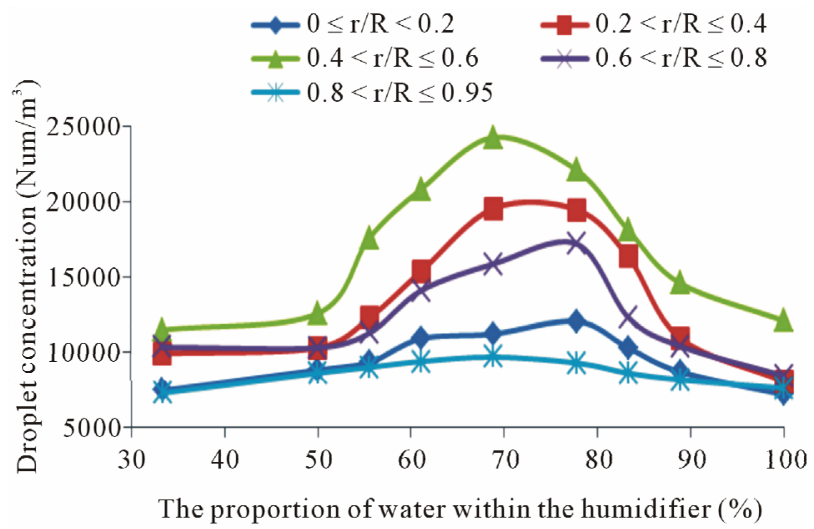

Figure 4. The case of different composite humidifier about humidifier water droplets under gravity concentration.

proportion of water, causing water to be atomized humidifier is not the same radius, and thus characterized as the trend of changes in droplet concentration. The proportion of the water tower humidifier below $50 \%$, little change in droplet concentration, may be too small amount of water inside the humidifier, the water can not be effectively atomized into droplets. Taking into account the different $r / R$ conditions, the maximum droplet concentration there changes in the scope, combined with the actual operation of the flue gas temperature, taking into account the vapor concentration in the flue gas desulfurization tower for drying droplet impact will increase within determine the wet weight of water in $60 \%$ to $75 \%$ range.

\subsection{The Size Distribution of Droplet}

In the experiment testing process, flue gas temperature control in $110^{\circ} \mathrm{C}-150^{\circ} \mathrm{C}$ in the fluctuations, the radial gas flow in the tower $4.82 \mathrm{~m} / \mathrm{s}-5.36 \mathrm{~m} / \mathrm{s}$, the total water in the $9 \mathrm{t} / \mathrm{h}$ under the conditions of analysis tower droplet size distribution, shown in Figure 5.

Figure 5 shows that, with the relative height increases, the droplet size of the overall trend showed lower, mainly because with the relative height increases, the droplet residence time is also increased by droplet spread and smoke and heat heat exchange between the droplets due to evaporation drying. Droplets from the dense central region of the tower to the wall showing the particle size reduction trend in the H/D $=1$ when the most obvious. At $\mathrm{r} / \mathrm{R}=0.7-0.95$ near wall region, $\mathrm{H} / \mathrm{D}=1-3$ range, there is a peak droplet size, mainly because with the relative height of the continuous extension droplets gradually cover the entire dense cross-section tower, spray droplets to the near wall region gradually become more, and with the growth of distance, droplet evaporation time is increased, resulting in the relatively near-wall particle size does not appear larger particles. Figure $\mathbf{5}$

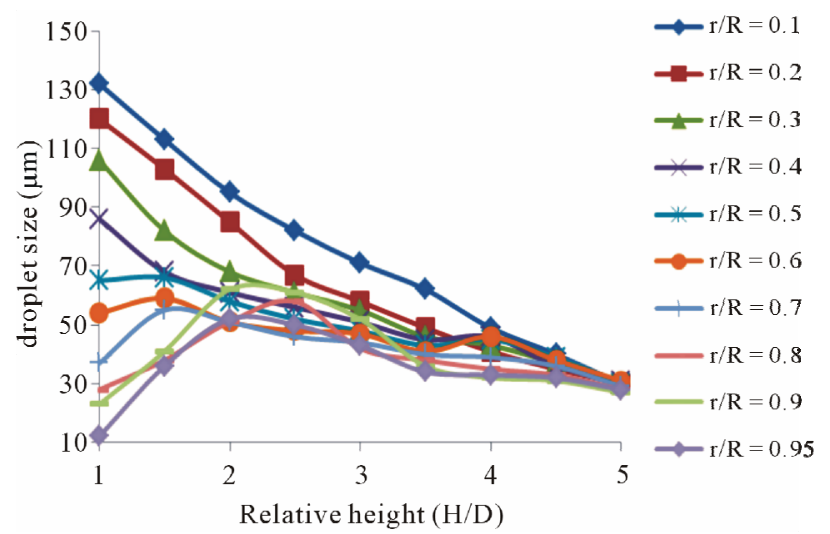

Figure 5. The droplets size distribution under the conditions of humidifying composite.

shows that, in different conditions, the relative radius of the same axis, the smaller droplet size range, the $\mathrm{H} / \mathrm{D}=5$, the droplet diameter is basically consistent, then the droplet will enter at the same speed the drying zone. Droplet size in the $r / R=0.7-0.95$ of the peak, the test with a nozzle to reach the maximum radius in the dense tower.

\subsection{The Desulfurization Efficiency under the Conditions of Compound Humidification}

In front of a number of conditions by variation of the analysis to determine the use of all devices on the desulfurization tower of the wind velocity field optimization; and chain mixing device through the increased role of spoiler axial velocity near the wall, increasing the desulfurization tower within the circulating turbulent flow region, the use of composite humidifier is designed to ensure fast and efficient desulfurization reaction liquid ion reaction time, while addressing some of the sticky wall and the effective utilization of water. This study examines the complex single-humidification and humidification conditions of the desulfurization efficiency under the conditions shown in Figure 6.

Figure 6 shows, the use of complex humidification mode, the average desulfurization efficiency from $82.8 \%$ to $86.7 \%$. Analysis of complex humidification effect on the desulfurization reaction may be in the following areas: Composite humidifier is still within the main focal reasonable optimize the concentration of solid particles with the ratio of wet to reduce the formation of particles, to improve the droplets and the sorbent probability of collisions between particles, while avoiding the sticky wall phenomenon; part of the outside water into the humidifier water in the form of dense phase desulfurization tower, reducing the flue gas temperature, making the dense smoke desulfurization tower temperature is controlled at a more reasonable desulfurization temperature 


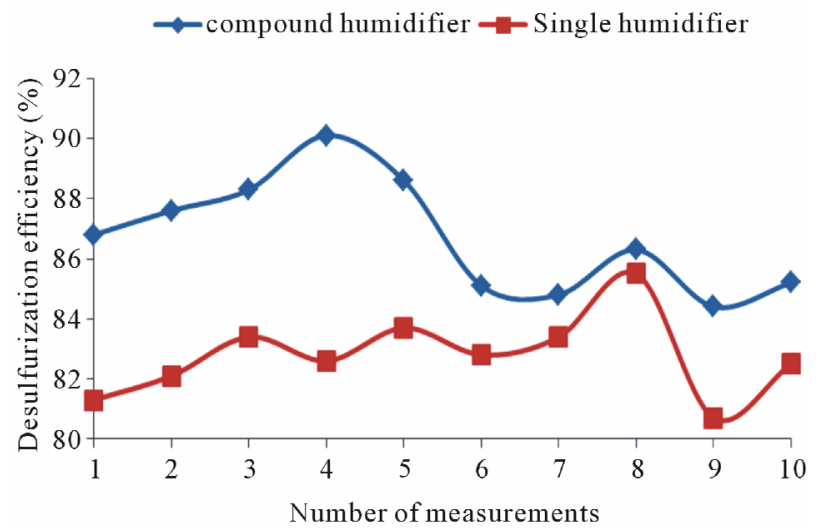

Figure 6. The desulfurization efficiency of different humidification methods under the conditions of the total amount of water $9 \mathbf{t} / \mathbf{h}$.

range, thus reducing the space by the use of slow gas desulfurization-solid desulfurization zone, an increase of fast ion liquid phase desulfurization zone, and thus characterized as an increase in desulfurization efficiency.

\section{Conclusion}

Humidifying composite approach does not change the dense gas desulfurization tower-solid-liquid phase of the reaction rule, but to optimize the desulfurization tower of dense particle concentration and droplet size, droplet size allows more close to the sorbent particle size, all of the solid-liquid two-phase between the effective collision rate. When the total water used in humidification humidifier water $60 \%$ to $75 \%$, you can increase the average desulfurization rate of about $4 \%$, so that the use of the original sorbent and process water under the premise of further reducing emissions to the air the total amount of sulfur dioxide, played a very good environmental performance.

\section{REFERENCES}

[1] G. D. Ma, "Air Pollution Control Technical Manual,"
Chemical Industry Press, Beijing, 2010.

[2] B. He, "Discussion on Sintering Flue Gas Desulphurizaion Technology in Iron and Steel Plant," Science Technology and Industry, Vol. 9, No. 7, 2009, pp. 100-102.

[3] Y. Q. Lu, "Fuel Gas Desulphurization Technology and Issues in Enterprises of National Heavy Industry," Environmental Engineering, Vol. 29, No. 1, 2011, pp. 80-82.

[4] X. Wei, W. L. Li, F. X. Fan and Z. L. Yuan, "Numerical Simulation Study on the Optimization of Gas-Solid TwoPhase Flows in a Desulfurization Tower," Proceedings of the Chinese Society for Electrical Engineering, Vol. 26, No. 7, 2006, pp. 12-18.

[5] G. Z. Gong, S. F. Ye, Y. F. Chen and Q. Xie, "Characterization and Modification of Inlet Configuration on Gas Flow in a Circulating Fluidized Bed Desulfurization Reactor," Journal of China University of Mining \& Technology, Vol. 39, No. 1, 2010, pp. 104-108.

[6] Y. G. Zhou, D. F. Wang, Y. F. Lu and M. C. Zhang, "Velocimetric Study of Gas-Solid Multiphase Flow in Topping Alkaline Atomizers," Journal of Power Engineering, Vol. 27, No. 2, 2007, pp. 273-277.

[7] P. R. Hu, L. Hui and Y. Q. Wang, "Experimental Research on Swirl Nozzle Spray Characteristics of Flue Gas Desulfurization System," Journal of Filtration \& Separation, Vol. 21, No. 1, 2011, pp. 20-23

[8] Z. J. Liu, J. L. Zhang and T. J. Yang, "Research and Development of Sintering Flue Gas Desulphurization Technology," China Metallurgy, Vol. 19, No. 2, 2009, pp. 1-5.

[9] F. Wang, H. M. Wang, F. Zhang, J. Lin, X. Q. Xue and J. Gao, "Mechanism and Industrial Application of Semi-Dry Flue Gas Desulphurization," Journal of Safety and Environment, Vol. 4, No. 1, 2004, pp. 26-28.

[10] L. Cui, L. Q. Zhang, L. Li, Y. Dong and C. Y. Ma, "Liquid-Solid Phase Concentration Distribution and Its Influence on Desulfurization Process under Composite $\mathrm{Hu}$ midification Way in CFB-FGD Tower," Proceedings of the Chinese Society for Electrical Engineering, Vol. 31, No. 17, 2011, pp. 59-66. 